\title{
Beratung, Begegnung und Bewegung - vielfältige Angebote für Patienten mit Morbus Bechterew
}

Rheumatische Erkrankungen beeinträchtigen auch die Lebensqualität - zu den körperlichen Schmerzen kommen meist auch mentale Herausforderungen und massive Einschränkungen im Alltag. Verschiedene Projekte - vom „Rockstar on a Mission“ über speziell entwickelte Bewegungskonzepte bis hin zur Verbesserung des Krankheitsverständnisses - wollen den Betroffenen Mut machen und ihre Situation verbessern.

„Morbus Bechterew hat mir beinahe viele der größten Freuden in meinem Leben genommen - wie meine Frau und Tochter zu umarmen oder live auf der Bühne zu performen", schildert Dan Reynolds, Frontsänger der Grammy-preisgekrönten Rockband Imagine Dragons seine persönlichen Erfahrungen im Rahmen der Kampagne, This AS Life“. Der 29-Jährige leidet seit fast zehn Jahren an Morbus Bechterew.

Dringend benötigte Informationen und Unterstützung in einer unterhaltsamen Weise zu bieten, ist das Ziel der von Reynolds gehosteten Talkshow von Menschen mit Morbus Bechterew für Menschen mit Morbus Bechterew: www.thisaslife.com

Die erste Episode von This AS Life Live! ist inzwischen auch unter www. leben-mit-bechterew.at ( $\bullet$ Abb. 1) verfügbar und zeigt, dass auch mit Morbus Bechterew ein sportliches, aktives Leben möglich ist.

\section{Die Krankheit hat viel von ihrem Schrecken verloren}

Entzündliche rheumatische Erkrankungen sind nach wie vor nicht heilbar, aber immer besser behandelbar, wie derWiener Rheumatologe Dr. Wolfgang Ebner ausführt: „Die Diagnose Morbus Bechterew bedeutet heute glücklicherweise für die Betroffenen nicht mehr unvermeidlich eine ausgeprägte Verkrümmung und Versteifung der Wirbelsäule. Durch verbesserte diagnostische Möglichkeiten und ein umfassendes Therapiemanagement mit modernen $\mathrm{Me}-$ dikamenten und konsequenten nicht medikamentösen Therapiestrategien wie Heilgymnastik und anderen Bewegungsübungen oder auch Kurbehandlungen - hat die Krankheit viel von ihrem Schrecken verloren."

\section{Beweglich bleiben}

"Die Physiotherapie ist ein wichtiger Eckpfeiler der Therapie von Morbus Bechterew und anderen rheumatischen Erkrankungen“, erklärt Dr. Theresa Kapral, Rheumatologin am Medizin Zentrum Alserstraße (MZA), die gemeinsam mit Anita Grassel, leitender Physiotherapeutin am MZA, das Konzept "Beweglich bleiben" entwickelt hat.

Aufgeteilt in die vier Bereiche Aufwärmen, Mobilisieren, Kräftigen und Dehnen soll das Konzept Betroffene bei ihrer Bewegungstherapie unterstützen sowie neue Ideen für leicht in den Alltag integrierbare Übungen liefern. Die Trainingsmaterialien (Aufsteller und DVD) können kostenlos unter novartis.austria@novartis.com bestellt werden.

\section{Einladung zur Patientenbefragung} Um künftige Initiativen noch besser an die Bedürfnisse der Betroffenen anpassen zu können, führt Novartis eine Patientenbefragung durch. Ziel ist eine umfassende Analyse der Herausforderungen, die mit Morbus Bechterew verbunden sind - vom Arbeitsmarkt über die Freizeitgestaltung bis hin zur Versorgungssituation.
Die Online-Befragung startet im Mai, der Link zur Befragung wird unter www.leben-mit-bechterew.at verfügbar sein. „Wir möchten Morbus Bechterew-Patienten in Österreich sehr herzlich einladen, an der Patientenbefragung teilzunehmen. Denn je mehr über die Lebensrealität Betroffener bekannt ist, desto punktgenauer können künftige Maßnahmen entwickelt werden", betont Dr. Wolfgang Bonitz, Medical Director Novartis Pharma.

rheuma plus $2017 \cdot 16: 45$

DOI 10.1007/s12688-017-0122-6

(c) Springer-Verlag Wien 2017

Quelle: Pressegespräch „Rheuma beweglich bleiben" der Novartis Pharma $\mathrm{GmbH}$, Wien, 27. April 2017

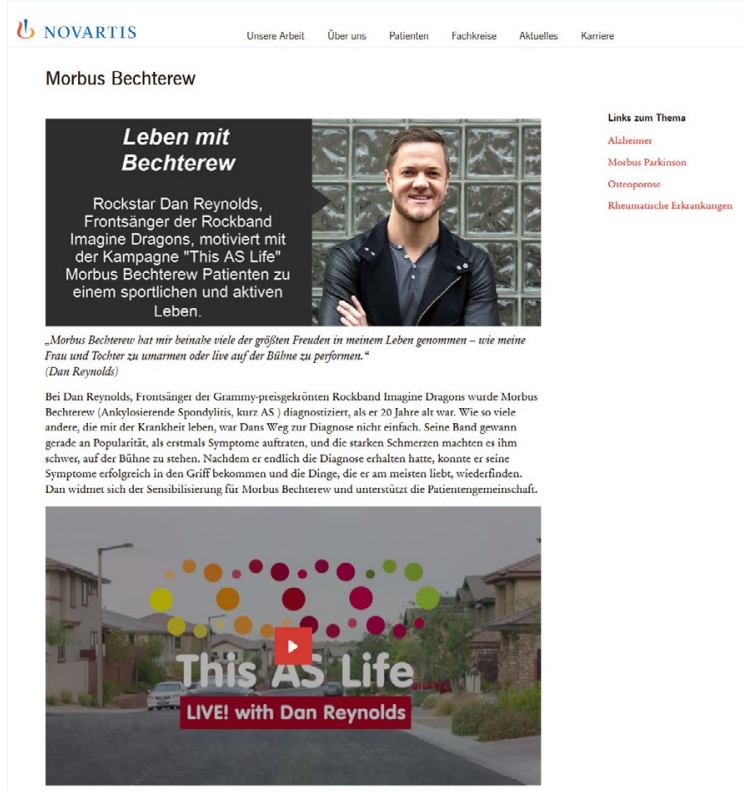

Abb. $1 \triangle$ Dan Reynolds ermutigt auch auf www.leben-mit-bechterew.at Morbus Bechterew-Patienten zu einem aktiven Lebensstil 